Michael Pontes de Abreu

As percepções inconscientes no pensamento de Gottfried W. Leibniz

Dissertação de Mestrado

Dissertação apresentada ao Programa de Pós-Graduação em Filosofia da Pontifícia Universidade Católica do Rio de Janeiro, como requisito parcial para obtenção do Grau de Mestre em Filosofia.

Orientadora: Profa. Déborah Danowski

Rio de Janeiro Fevereiro de 2003 
Michael Pontes de Abreu

\title{
As percepções inconscientes no pensamento de Gottfried W. Leibniz
}

Dissertação apresentada como requisito parcial para obtenção do Grau de Mestre pelo Programa de Pós-graduação em Filosofia do Departamento de Filosofia do Centro de Teologia e Ciências Humanas da PUC-Rio. Aprovada pela Comissão Examinadora abaixo assinada.

\author{
Profa. Déborah Danowski \\ Orientadora \\ Departamento de Filosofia - PUC-Rio
}

Profa. Vera Cristina de Andrade Bueno

Departamento de Filosofia - PUC-Rio

Prof. Ulysses Pinheiro

UFRJ

Prof. Jügen Heye

Coordenador Setorial do Centro

de Teologia e Ciências Humanas - PUC-Rio

Rio de Janeiro,

de 2003. 
Aos meus pais, Neli Pontes de Abreu e José Caetano de Abreu. 


\section{Agradecimentos}

À minha orientadora Professora Déborah Danowski.

À CAPES e à PUC-Rio, pelos auxílios concedidos, sem os quais este trabalho não poderia ter sido realizado.

À Georgia Amitrano e Milla Maria, pelo apoio em todas as horas.

Ao pessoal da diretoria, pela dedicação, assiduidade e companheirismo.

Aos meus amigos Luciano, Flávio, Alessandro e Eleonora, Beto, Felipe, Alexandre e Ana Cristina, Sílvio, Praça, Favaretto, Ronald e Renatinha.

Aos meus colegas da PUC-Rio.

Aos professores que participam da comissão examinadora.

A todos os funcionários e professores do Departamento de Filosofia da PUC-Rio. 
Todos os direitos reservados. É proibida a reprodução total ou parcial do trabalho sem a autorização da universidade, do autor e da orientadora.

Michael Pontes de Abreu

Graduou-se em filosofia pela Universidade Federal do Rio de Janeiro em 2001. Estagiou na Fundação Oswaldo Cruz na condição de jovem pesquisador Pibic-CNPq do Núcleo de Filosofia e Ciências da Vida e da Saúde. Promoveu vários eventos e congressos na área de filosofia e ciência humanas enquanto aluno de graduação. Participou de diversos eventos na área de filosofia.

Ficha Catalográfica

Abreu, Michael Pontes de

As percepções inconscientes no pensamento de Gottfried W. Leibniz / Michael Pontes de Abreu; orientadora Déborah Danowski. - Rio de Janeiro : PUC, Departamento de Filosofia, 2003.

[8], 103 f. ; $30 \mathrm{~cm}$

Dissertação (mestrado) - Pontifícia Universidade Católica do Rio de Janeiro, Departamento de Filosofia.

Inclui referências bibliográficas.

1. Filosofia - Teses. 2. Leibniz, Gottfried W. 3. Filosofia moderna. 4. Percepções inconscientes. 5. Pequenas percepções. 6. Consciência. 7. Apercepção. 8. Atenção. I. Danowski, Déborah. II. Pontifícia Universidade Católica do Rio de Janeiro. Departamento de Filosofia. III. Título.

CDD: 100 


\section{RESUMO}

De Abreu, Michael Pontes; Danowski, Deborah. As Percepções Inconscientes no Pensamento de Gottfried W. Leibniz. Rio de Janeiro, 2003. p.111. Dissertação de Mestrado. Departamento de Filosofia, Pontifícia Universidade Católica do Rio de Janeiro.

Atentando para a importância manifesta que as percepções inconscientes desempenham no pensamento de Leibniz, essa pesquisa tem por objetivo apresentar um exame minucioso de sua natureza, e de como elas se inserem nas argumentações desenvolvidas pelo filósofo. Para tanto, elegemos a obra Novos Ensaios sobre o Entendimento Humano (1704) como base de nossas investigações, por considerarmos que ela seja o escrito onde o autor mais minuciosamente trata do tema que nos propomos a examinar.

Participando quase que integralmente de todos os temas analisados por Leibniz nos Novos Ensaios, o conceito de percepção inconsciente, além de apresentar uma grande amplitude teórica, adquire também um número considerável de matizes conforme se insere nos diferentes contextos examinados, perfazendo um conceito de difícil entendimento. Por conta disso, dividimos nossa Dissertação em duas partes, buscando compreender in abstrato, ou seja, da maneira mais geral possível, qual a natureza dessas percepções, para apenas em seguida analisarmos como elas efetivamente se inserem nas diferentes temáticas examinadas na obra, a saber: conhecimento, moral, psicologia e metafísica.

Palavras-Chave: Leibniz, filosofia moderna, percepções inconscientes, pequenas percepções, consciência, apercepção, atenção. 


\section{RÉSUMÉ}

De Abreu, Michael Pontes; Danowski, Deborah. Les Perceptions Inconscientes dans la Pensée de Gottfried W. Leibniz. Rio de Janeiro, 2003. p.111. Dissertation. Departamento de Filosofia, Pontifícia Universidade Católica do Rio de Janeiro.

Le but de cette recherche est l'examen détaillé du concept de perception inconsciente dans la pensée de Leibniz, et du rôle - par ailleurs fondamental - que lui est assigné dans l'argumentation developpée par l'auteur. Pour ce faire, nous avons élu les Nouveaux essais sur l'entendement bumain (1704) comme la base de notre investigation. La raison de ce choix ne saurait sinon se rattacher au traitement minutieux donné par Leibniz au concept de perception inconsciente dans cet ouvrage.

Le concept de perception inconsciente prend sa part dans la discussion de presque tous les thèmes analysés par Leibniz dans les Nouveaux essais, et il y acquiert ainsi un nombre considérable de nuances. La division de notre Dissertation en deux parties répond à cette complexité. Dans la première, nous cherchons à comprendre la nature des perceptions inconscientes; dans la seconde, nous nous appliquons à analyser comment elles trouvent leur place vis-à-vis de la plupart des thèmes explorés dans l'ouvrage en question, à savoir: connaissance, morale, psychologie, physique, et métaphysique.

Mots clefs: Leibniz, philosophie moderne, perceptions inconscientes, petites perceptions, conscience, aperception, attention. 


\section{SUMÁRIO}

$\begin{array}{ll}\text { Introdução } & 9\end{array}$

$\begin{array}{ll}\text { Abreviação } & 12\end{array}$

$\begin{array}{ll}\text { Advertância } & 13\end{array}$

$\begin{array}{ll}\text { Parte I. O conceito de percepção inconsciente } & 15\end{array}$

$\begin{array}{ll}\text { Intróito } & 16\end{array}$

Cap.1. Da faculdade de perceber, da percepção e dos objetos da $\begin{array}{ll}\text { percepção } & 18\end{array}$

$\begin{array}{ll}\text { Cap.2. Da consciência } & 24\end{array}$

Cap.3. Da fragilidade do corpo orgânico e os limites dos órgãos sensoriais

Cap.4. Dos graus da apercepção humana em relação às idéias do $\begin{array}{ll}\text { entendimento } & 42\end{array}$

Cap.5. Definição do conceito de percepçäo inconsciente

Parte II. A prova da existência das percepções inconscientes e o papel que elas desempenham no desenvolvimento da filosofia de $\begin{array}{ll}\text { Leibniz } & 52\end{array}$

Cap.1. A prova da existência das percepções inconscientes 53

Cap.2. As percepções inconscientes e o conhecimento 58

Cap.3. As percepções inconscientes e a moralidade 66

$\begin{array}{ll}\text { Cap.4. As percepções inconscientes e a psicologia } & 79\end{array}$

Cap.5. As percepções inconscientes e a metafísica 83

$\begin{array}{ll}\text { Conclusão } & 100\end{array}$

$\begin{array}{ll}\text { Bibliografia } & 108\end{array}$ 